Journal of Social Sciences (COES\&RJ-JSS)

ISSN (E): 2305-9249 ISSN (P): 2305-9494

Publisher: Centre of Excellence for Scientific \& Research Journalism, COES\&RJ LLC.

Online Publication Date: $1^{\text {st }}$ October 2019

Online Issue: Volume 8, Number 4, October 2019

https://doi.org/10.25255/jss.2019.8.4.558.573

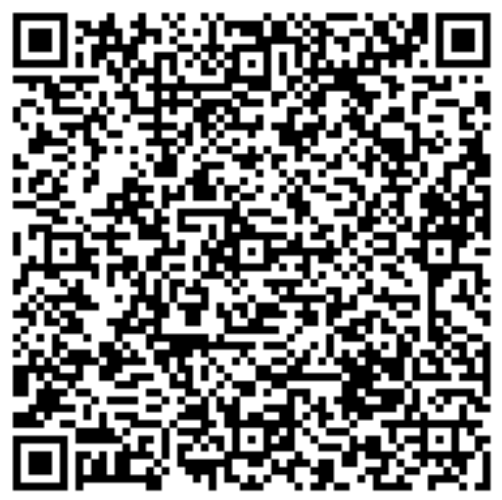

\title{
Factors affecting performance of Jordanian Insurance Corporations
} in Jordan

Ebtehal Al-Ma'aeteh, Tasneam Basyouni, Malak Smadi, Tesneam Saleh, Feras Alrawashdeh and S. Al Wadi

Department of risk management and insurance, the University of Jordan, Jordan Abstract:

The study aimed at determining the degree of influence of both the economic environment and the competitive environment on the financial performance of the Jordanian insurance companies. The study found that there is an impact of the economic environment and competitive environment on financial performance in the Jordanian insurance companies to a high degree. The study also showed that there is no statistically significant effect on the gender variable on the opinions of the study sample members on the financial performance of the Jordanian insurance companies, but there is a statistically significant effect of the job title variable on the opinions of the sample members on the financial performance of the Jordanian insurance companies. The study recommended to measure and evaluate the institutional performance and review and update the performance of the institution for the intended output.

Key words:

Economic environment, competitive environment, financial performance of insurance companies

\section{Citation:}

Al-Ma'aeteh, Ebtehal; Basyouni, Tasneam; Smadi, Malak; Saleh, Tesneam; AlRawashdeh, Feras; Al-Wadi, Sadam(2019); Factors affecting performance of Jordanian Insurance Corporations in Jordan; Journal of Social Sciences (COES\&RJJSS), Vol.8, No.4, pp:558-573; https://doi.org/10.25255/jss.2019.8.4.558.573. 


\title{
Journal of Social Sciences (COES\&RJ-JSS), 8(4), pp.558-573
}

\author{
العوامل المؤثرة في تقييم الأداء المالي على شركات التأمين في الاردن \\ ابتهال ماجد المعايطة_قسم إدارة المخاطر و التأمين_الجامعه الاردنيه

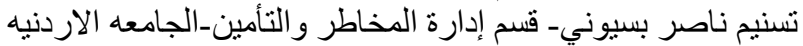

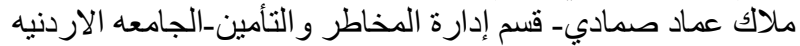

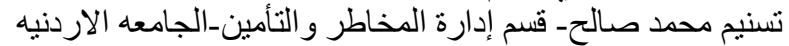

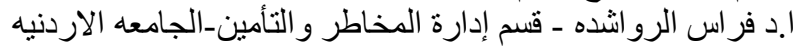

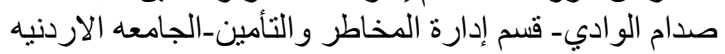

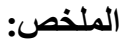

هدفت الدراسة تحديد درجة تأثيركل من العوامل البيئة الاقتصادية والبيئة التنافسية على الاداء المالئي

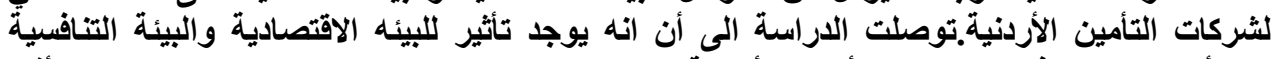

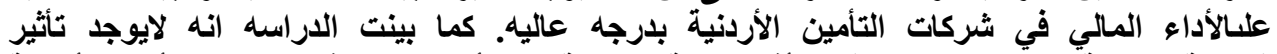

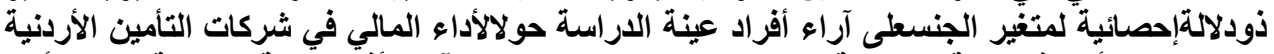

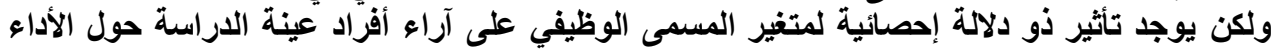

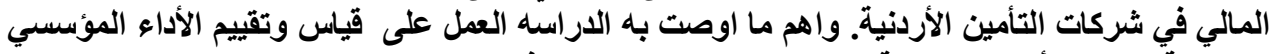

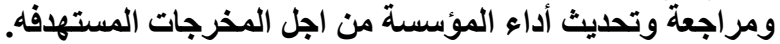

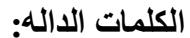
البيئة الاقتصادية ، والهة: والبيئة التنافسية ،الأداء المالي لثركات التأمين .

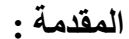

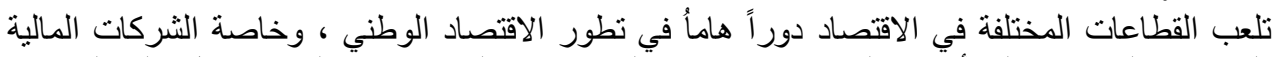

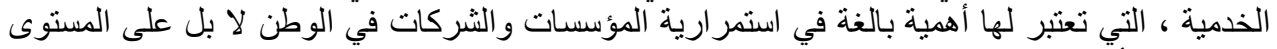

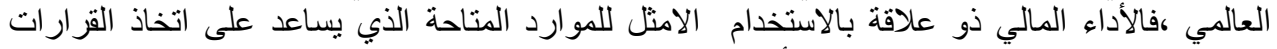

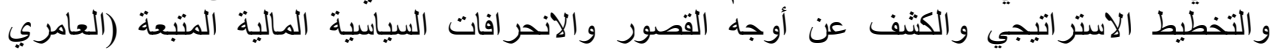

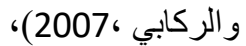

(Al rawashdeh,2016)

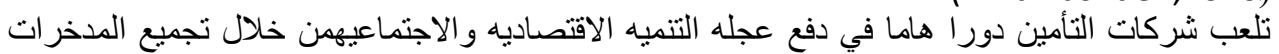

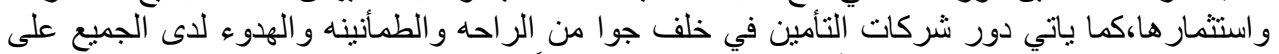

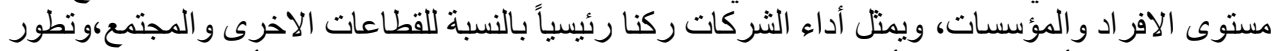

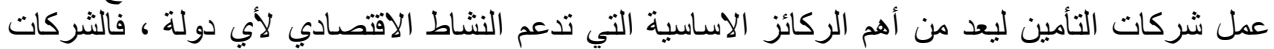

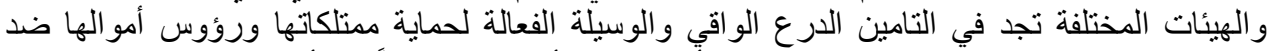

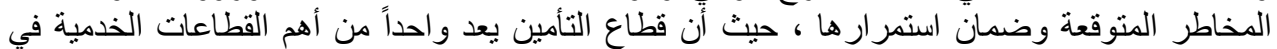

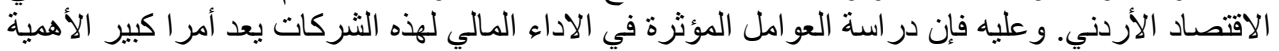

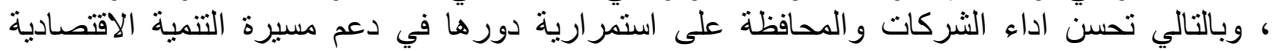

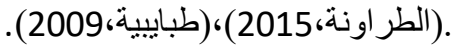

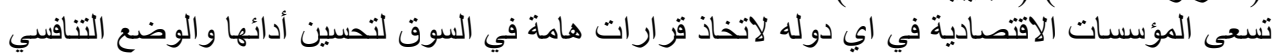

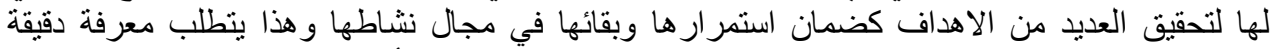

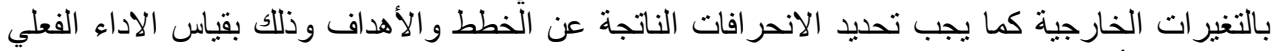

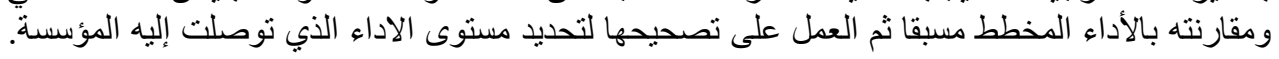

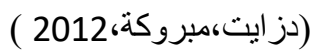

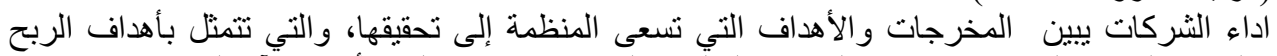

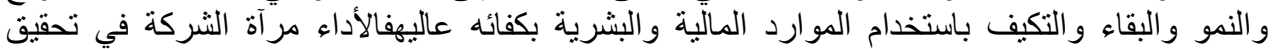

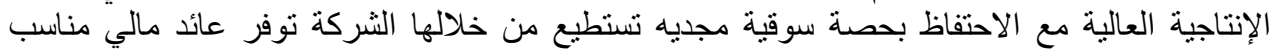
(توفيق ،2004 (عبد القادر ، 2012). 


\section{Factors affecting performance of Jordanian Insurance Corporations in Jordan}

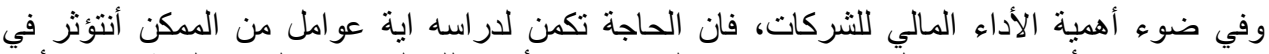

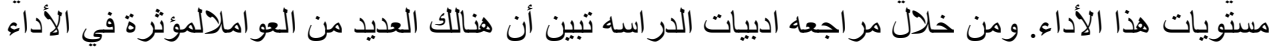

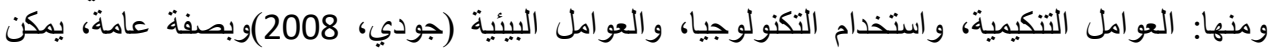

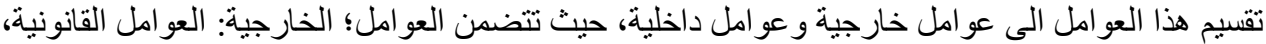

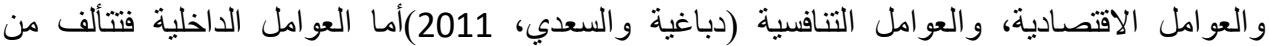
التخطيط المالي، و الرقابة الداخلية، والكفاءة الادارية (الوردات، ولئ، 2010)

مشكلة الاراسة:

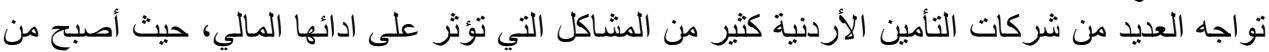

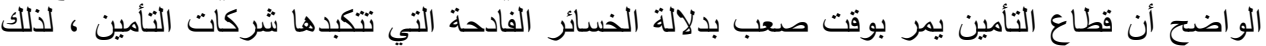

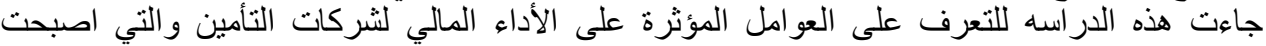

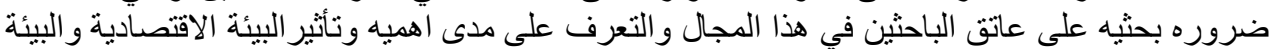

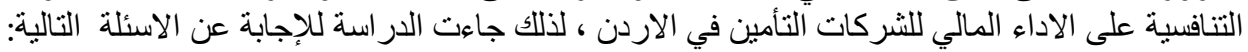

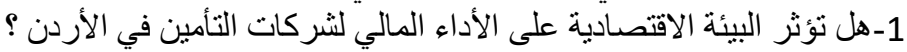

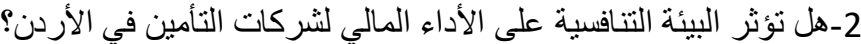

3- ما درجة تأثير الأداء المالي في شركات التأئ التأمين الأردنية؟

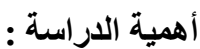

جاءت هذه الدر اسهة من اهميه القطاع الذي يلعب دور ال رياديا في الاقتصاد الوطني، ودر استة العو امل المؤثرة

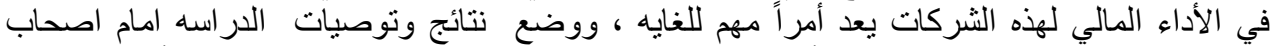

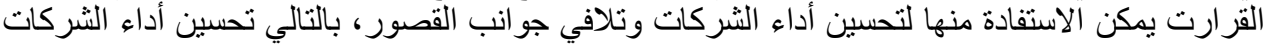

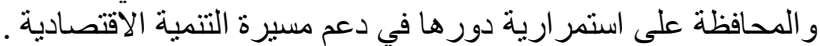

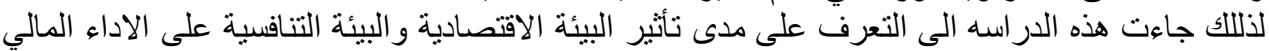
للشركات التأمين في الاردن.

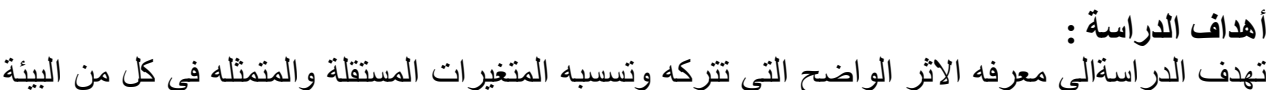

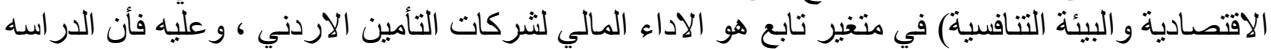
تسعى لتحقيق الاهداف التاليه.

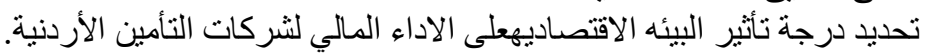

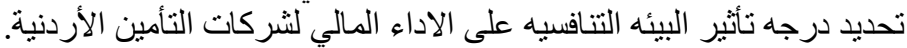

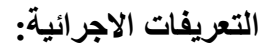

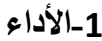

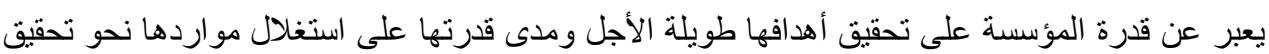

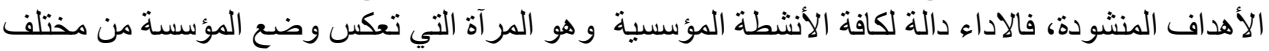
جو انبها، وتسعى كافة الأطر اف في المنظمة إلى تعزيز الأداء الأمثل .( قمر ، 2009).

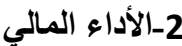

هو قدرة المؤسسة على تحقيق أهدافها المالية باستخدام الوسائل المالية المتاحة و يتجسد في قدرة المؤسسة على تحقيق التوازن المالي وتوفير السيولة اللازمة لتسديد ما عليها ولتحفيق معدل مردودية التية جيدة وتكاليف 


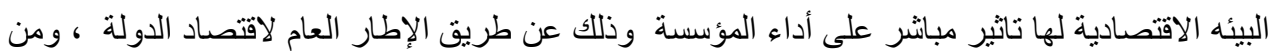

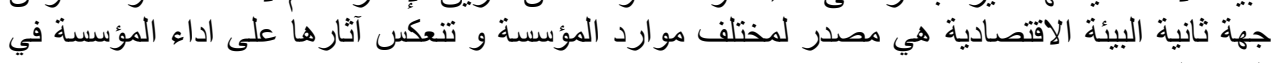

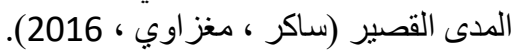

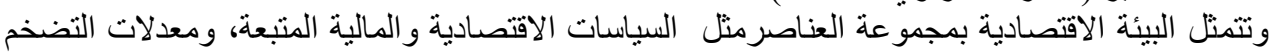
و البطالة وخصائص البينة الإستنمار ، ومعدلات الفيائدة (در اجي، 2010) 4-البيئة التنافسية و البهية

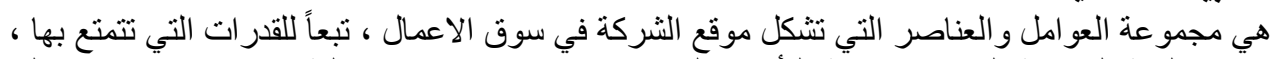

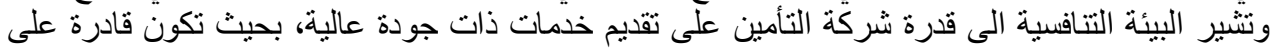
منافسة مثيلاتها المحلية ، وعرض خُّة خدات جديدة في السوق ، و و القدرة على الابتكار و الإبداع ـ (الطراونة ،

. (2015

5- شركات التأمين في الاردن :

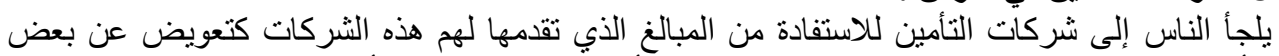

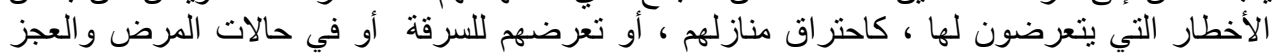

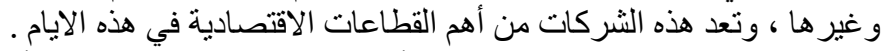

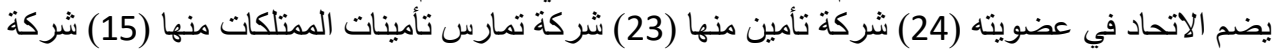

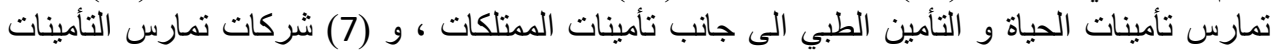

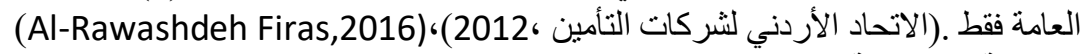

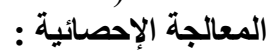
تم استخدام الاختبار ات الاحصيائية التالية:SPSSمن خلال الحزمة الاحصائية

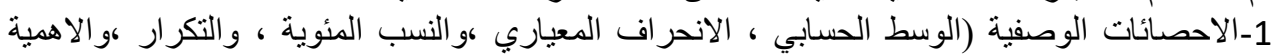
النسبية التي حددت من خلال الومنة الصيغة التالية :

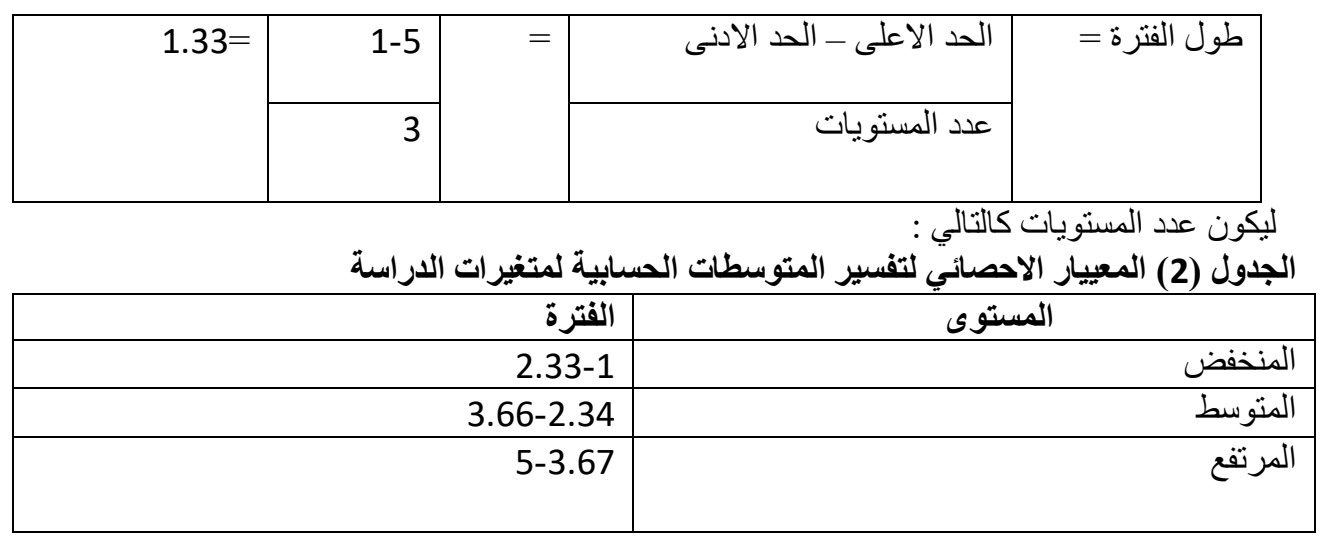

2- (Independent sample T-test).

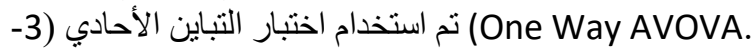
4- تم استخدام تحليل الانحدار المتعدد والبسيط.

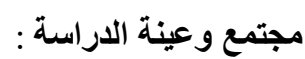

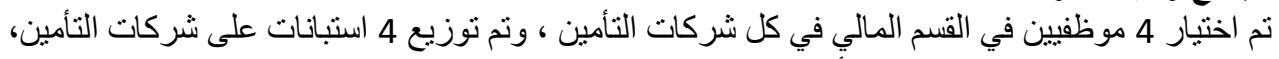

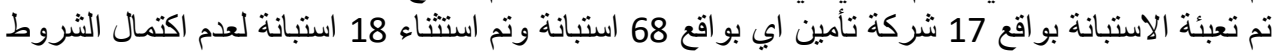

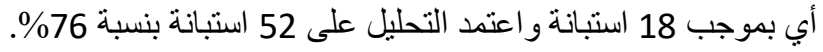




\section{Factors affecting performance of Jordanian Insurance Corporations in Jordan}

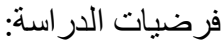

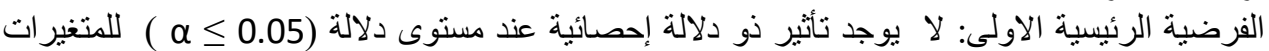
المستقلة (البيئة الاقتصادية، البيئة التتافسية) على الأداء الئلة دالي في شركات التأمين الأردنية.

الفرضية الفرعية الاولى من الرئيسية الأولى: لا يوجد تأثير ذو دلالة إحصائية عند مستوى دلالة (0.05 الألئ a ) للبيئة الاقتصادية على الأداء المالي في شركات التأمين الأردنية.

الفرضية الفرعية الثانية من الرئيسية الأولى: لا يوجد تأثير ذو دلالة إحصائية عند مستوى دلالة (0.05 a ) للبيئة التنافسيه على الأداء المالي في شركات التأمين الأردنية.

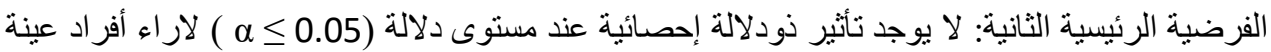

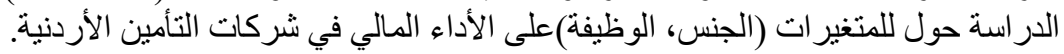

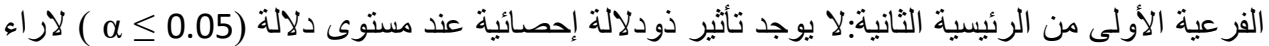
أفراد عينة الدر اسة حول متغير الجنس على الأداء المالي في شركات التالية التأمين الأردنية.

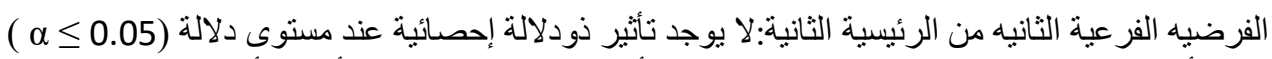
لار اء أفراد عينة الدر اسة حول متغير الوظيفه على الأداء المالي في شركات التئ التأمين الأردنية.

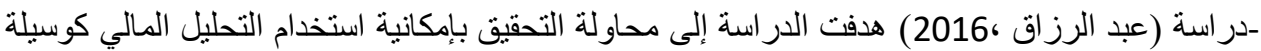

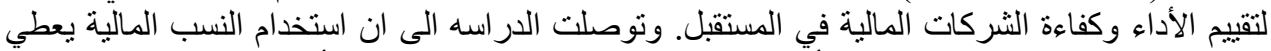

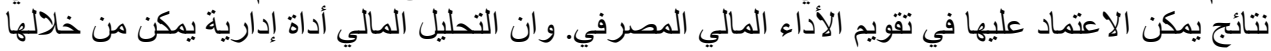

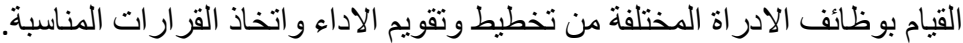

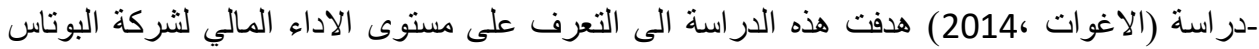

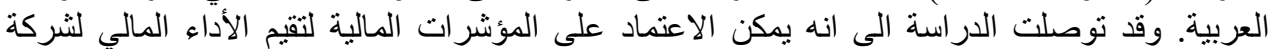

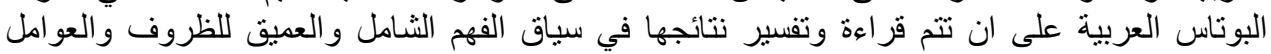

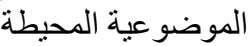

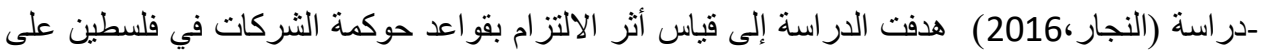

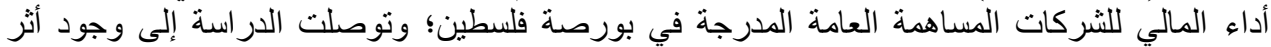

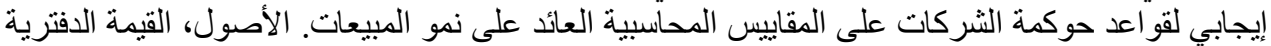

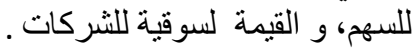

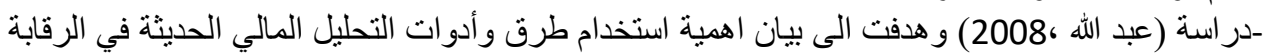

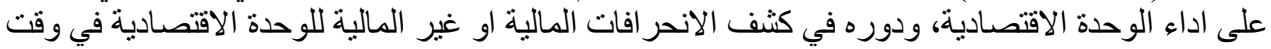

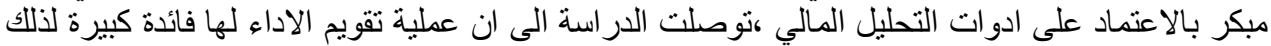

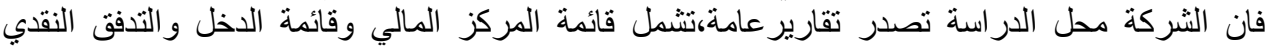

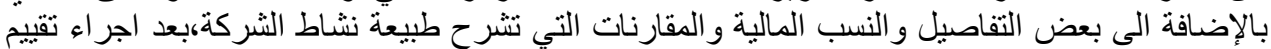

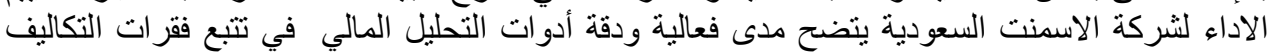

وتحليلها.

دراسه (DeitianaTita, Habibuw Lionel, 2015) حول الأداء المالي وهو أحد العوامل التي

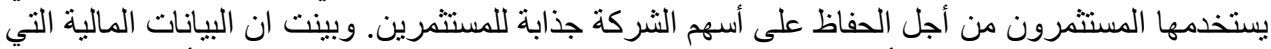

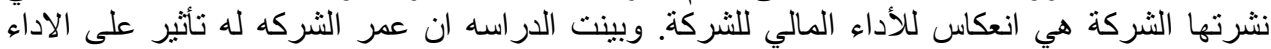

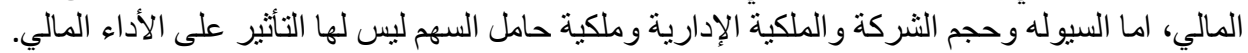

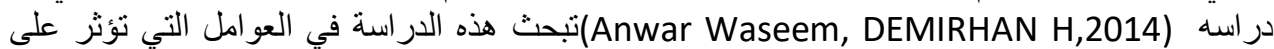

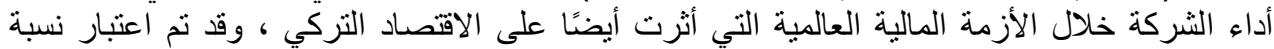




\section{Journal of Social Sciences (COES\&RJ-JSS), 8(4), pp.558-573}

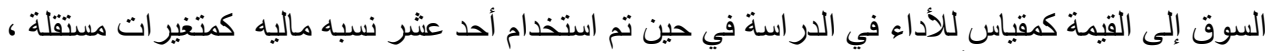

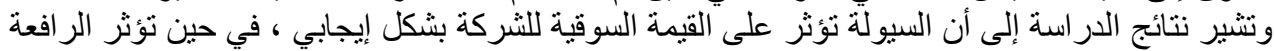

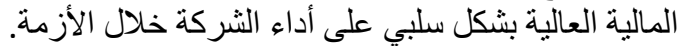

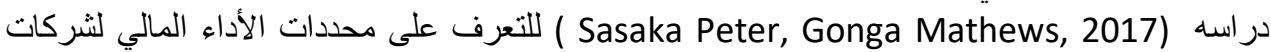

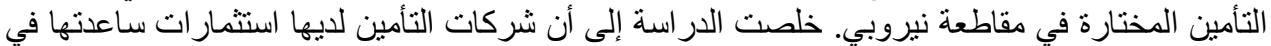

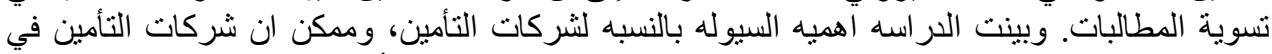

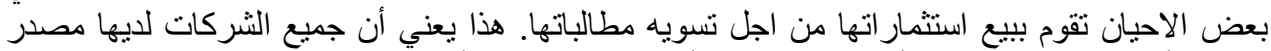

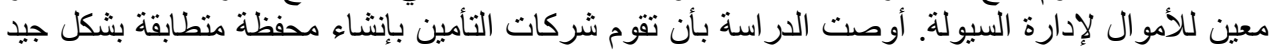

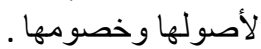

الطراونة ، أنس، (2015)هدفت الدراسه الى اختبار العوامل الخارجية مثل البيئة القانونية، و البيئة

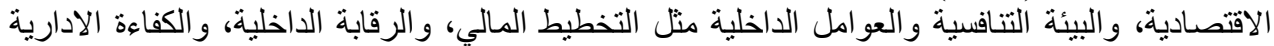

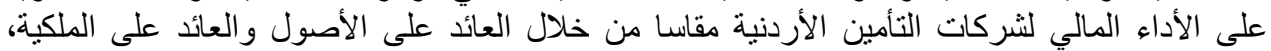

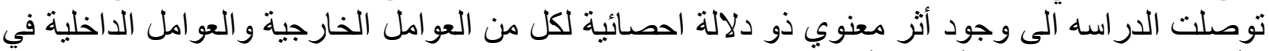

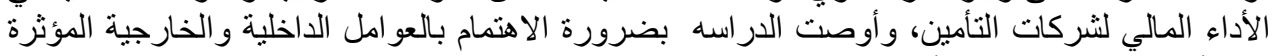
في الأداء المالي لثركات التأمين.

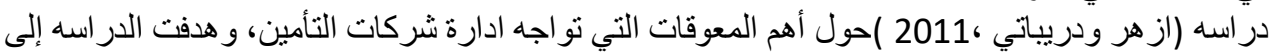

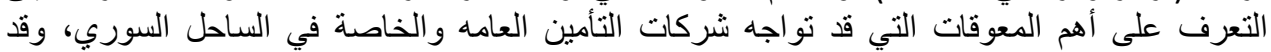

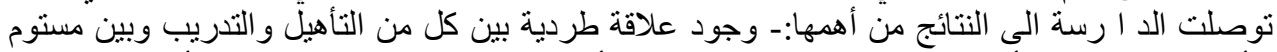

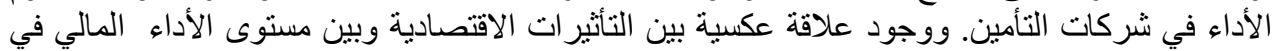

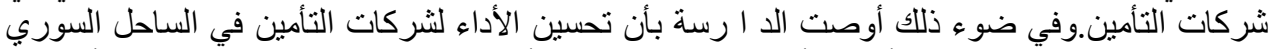

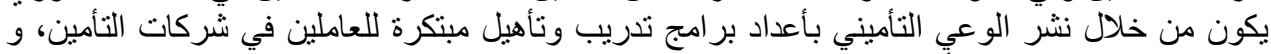
ضرورة تعاون شركات التأمين مع الجهات المختصة لتبني الارشادات و الاجر اءات التي تمنع وقو فئرع الخطر

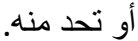

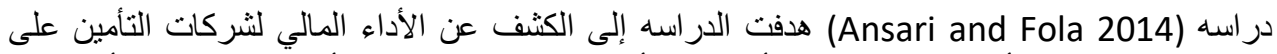

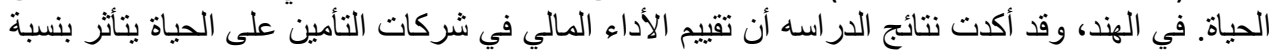

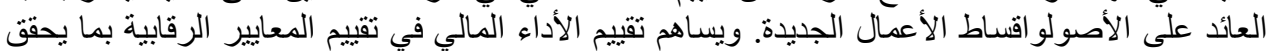

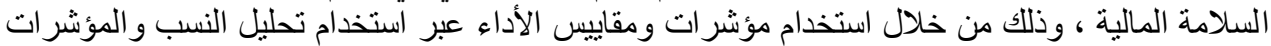

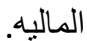

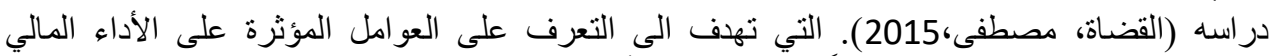

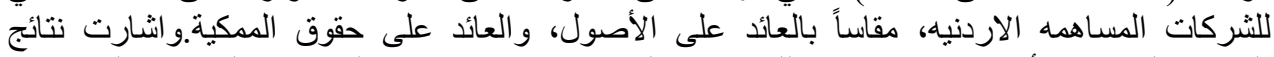

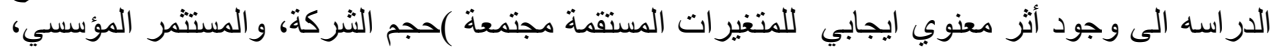

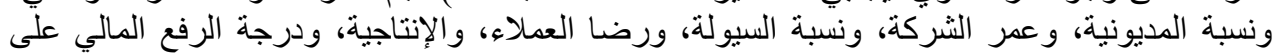

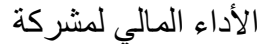

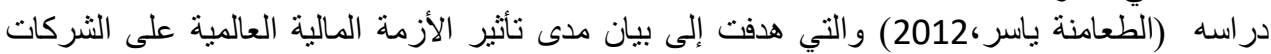

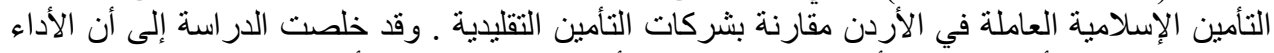

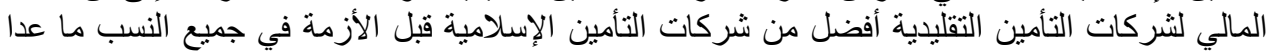

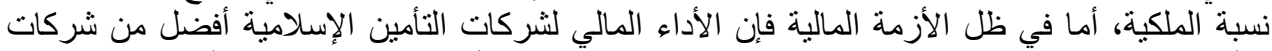

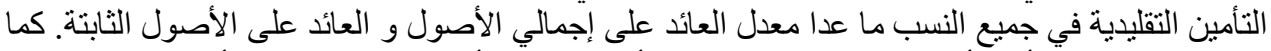
بينت نتائج الدراسة أن الأداء الاقتصادي لثركات التأمين التقليدية أفضل من شركات التأمين الإسلامية قبل الإل التئة

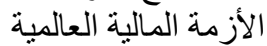

دراسه (عليان، 2009) والتي تهدف الى الى بيان أهمية استخدام الموازنات التخطيطية في عملية التخطيط

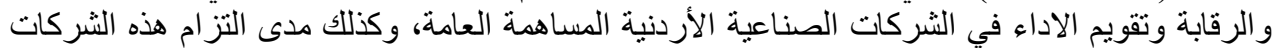

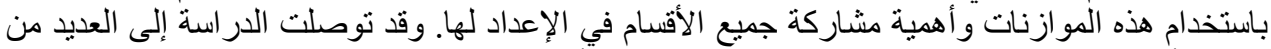

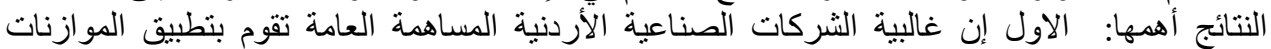

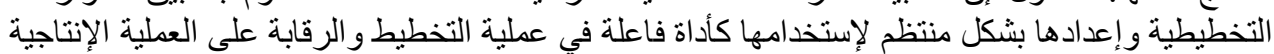




\section{Factors affecting performance of Jordanian Insurance Corporations in Jordan}

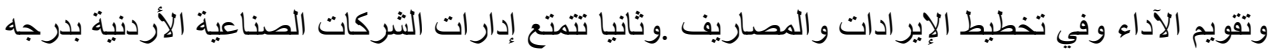

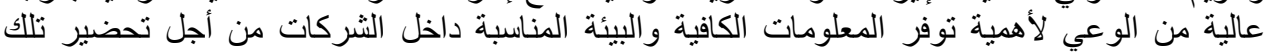
الموازنات.

$$
\text { نتائج وتوصيات الدراسة (التحليل الاحصائي ): }
$$

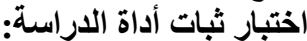
لاختبار ثبات أداة الدر اسة نم ايجاد معاكلات كرونباخ ألفا، و الجدول الآتي يبين ذلك:

الجدول1. معاملات كرونباخ ألفا لاختبار ثبات أداة الدراسة

\begin{tabular}{|c|c|}
\hline معامل كرونباخ ألفا & البع \\
\hline 0.84 & البيئة الاقتصادية \\
\hline 0.89 & البيئة التنافسية \\
\hline 0.86 & الأداء المالي \\
\hline
\end{tabular}

من خلال الجدول السابق نلاحظ أن جميع قيم معاملات كرونباخ ألفا صالحة لغايات الدر اسة.

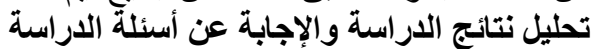
توزيع أفراد عينة الاراسة: الجدول(1). توزيع أفراد عينة الدراسة تبعاً للعوامل الثخصية

\begin{tabular}{|c|c|c|c|}
\hline النسبة المئوية & التكر ار & الفئة & المتغير \\
\hline 75 & 39 & ذكر & \multirow{2}{*}{ النوع الاجتماعي } \\
\hline 25 & 13 & أنثى & \\
\hline 13.5 & 7 & من 25 سنة فأقل & \multirow{4}{*}{ 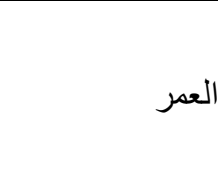 } \\
\hline 44.2 & 23 & من 26-35 سنة & \\
\hline 36.5 & 19 & من 36-45 سنة & \\
\hline 5.8 & 3 & من 46-55 سنة & \\
\hline 3.8 & 2 & مدير مالي & \multirow{5}{*}{ المستوى الوظيفي } \\
\hline 15.4 & 8 & رئيس محاسبين & \\
\hline 65.4 & 34 & محاسب & \\
\hline 3.8 & 2 & مدقق داخلي & \\
\hline 11.5 & 6 & مدقق خارجي & \\
\hline 78.8 & 41 & محاسبة & \multirow{4}{*}{ التخصص العلمي } \\
\hline 1.9 & 1 & نظم معلومات إدارية & \\
\hline 3.8 & 2 & اقتصساد & \\
\hline 15.4 & 8 & مالية & \\
\hline 90.4 & 47 & بكالوريوس & \multirow{3}{*}{ المؤهل العلمي } \\
\hline 1.9 & 1 & دبلوم در اسات عليا & \\
\hline 7.7 & 4 & ماجستير & \\
\hline 3.8 & 2 & أقل من سنة & \multirow{3}{*}{ الخبرة العلمية } \\
\hline 23.1 & 12 & من 2-أقل من 5 سنوات & \\
\hline 32.7 & 17 & من 5-أقل من 10 سنو ات & \\
\hline
\end{tabular}




\section{Journal of Social Sciences (COES\&RJ-JSS), 8(4), pp.558-573}

\begin{tabular}{|r|r|r|r|}
\hline 40.4 & 21 & من & \\
\hline 100 & 52 & Total & \\
\hline
\end{tabular}

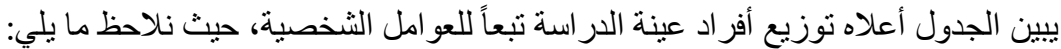

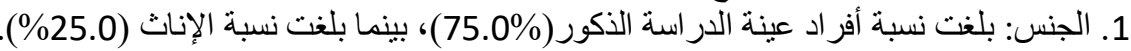

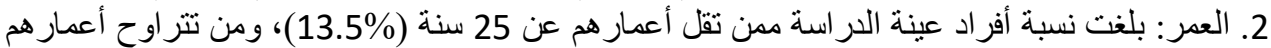

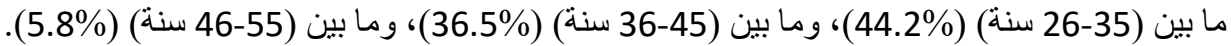

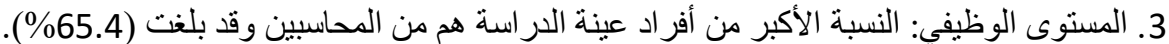

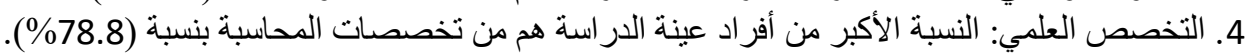

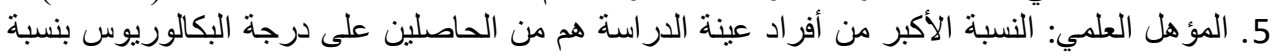
. $(\% 90.4)$

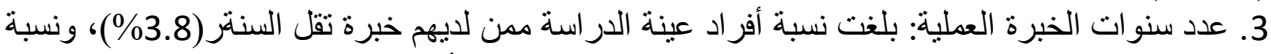

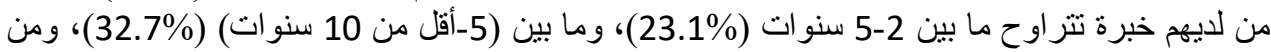

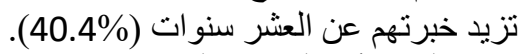
الاجابة عن أسئلة الاراسة الثنة

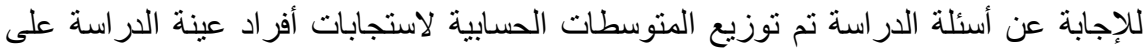

أسئلة الاستبيان باعتماد المعايير التالية:

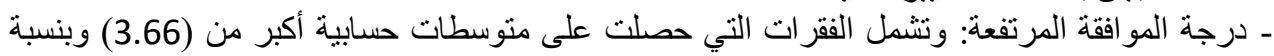
مئوية أكبر من (73.2\%). ـ درجة المو افقة المتوسطة: وتتشمل مجموعة الفقر ات التي تراوحت متوسطاتها الحسابية بين (73.2.34-3.66) وبنسبة مئوية (73. (73.2\%-4). ـ درجة المو افقة المتدنية: وتشمل مجموعة (73.8\%ة الفقرات التي حصلت على متوسطات حسابية أقل من (2.34) وبنسبة مئوية أقل من (46.8\%).

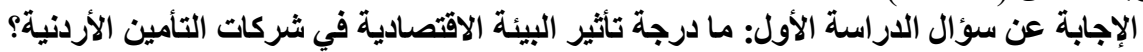

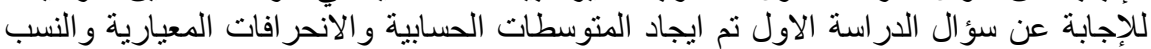
و الدرجات، و الجدول الآتي يبين ذلك: للك:

الجدول (2). المتوسطات الحسابية والاتحرافات المعيارية للفقرات المعبرة عن البيئة الاقتصادية

\begin{tabular}{|c|c|c|c|c|}
\hline 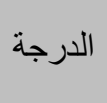 & $\%$ & الانحر اف المعياري & الحسابي & 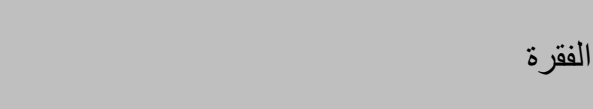 \\
\hline مرتفعة & 90.4 & 0.727 & 4.52 & التخطيط الاستر اتيجي يؤثر على نمو الثركة \\
\hline مرتفعة & 89.2 & 0.67 & 4.46 & يلى إير الدات شركات الأنأمين. في معدل دخل الفرد \\
\hline مرتفعة & 87.4 & 0.595 & 4.37 & التضخم الركودي أثر على أداء شركات التأمين \\
\hline مرتفعة & 86.6 & 0.785 & 4.33 & تؤثر الفجوة الركودية على أداء شركات التأمين \\
\hline مرتفعة & 86.2 & 0.701 & 4.31 & تؤُثر معدلات التضخم على الاداء المالي للشركات \\
\hline مرتفعة & 85 & 0.988 & 4.25 & على حجم الضبر ائب المباتشرة وغير المباثرة تؤثر \\
\hline مرتفعة & 84.6 & 1.113 & 4.23 & التامتفين. معدل البطالة يؤثر على شراء خدمات \\
\hline
\end{tabular}


Factors affecting performance of Jordanian Insurance Corporations in Jordan

\begin{tabular}{|c|c|c|c|c|}
\hline مرتفعة & 84.2 & 0.893 & 4.21 & تأٔثَثر معدلات الفائدة على استثمارات شركات \\
\hline 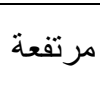 & 79.6 & 1 & 3.98 & تقؤثر شركات التأمين الفائدة على حجم الخدمات التى \\
\hline مرتفعة & 75.4 & 0.921 & 3.77 & تؤثر العولمة على أداء شركات التأمين. \\
\hline مرتفعة & 85.28 & 0.524 & 4.26 & البيئة الاقتصادية \\
\hline
\end{tabular}

يتضح من الجدول أعلاه أن جميع الفقرات المعبرة عن درجة تأثنير البيئة الاقتصادية في شركات

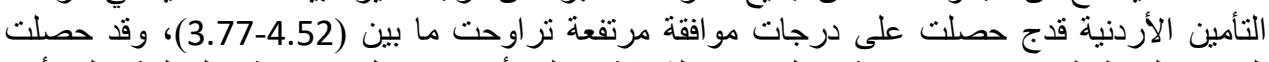

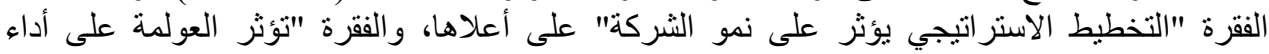

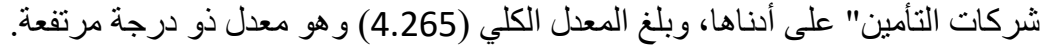
مما سبق يتبين أن درجة تأثبير البيئة الاقتصادية في شركات التأمين الأردنية كانت بدرجة

الإجابة عن سؤال الدراسة الثاني: ما درجة تأثير البيئة التنافسية في شركات التأمين الأردنيةج

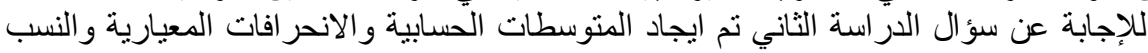
و الدرجات، و الجدول الآتي يبين ذللك:

الجدول (3). المتوسطات الحسابية والاتحرافات المعيارية للققرات المعبرة عن البيئة التنافسية

\begin{tabular}{|c|c|c|c|c|}
\hline الدرجة & $\%$ & 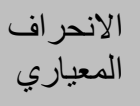 & 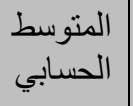 & الفقرة \\
\hline مرتفعة & 91.6 & 0.605 & 4.58 & الابتكار ، ورضية الموظفين يؤثر على قاءرة والإنتاجية الثركة على \\
\hline مرتفعة & 89.6 & 0.671 & 4.48 & الابداع المنافسة بين الثرار للارتفاع بأداء الثرضكات. ضرورة \\
\hline مرتفعة & 88.8 & 0.608 & 4.44 & 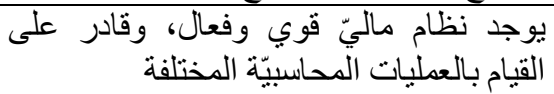 \\
\hline مرتفعة & 88.8 & 0.669 & 4.44 & 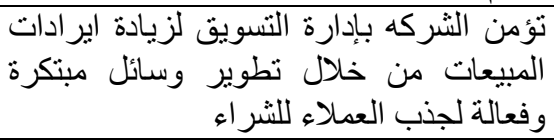 \\
\hline مرتفعة & 88.4 & 0.723 & 4.42 & الآصنافسة مع الثركات السمالية للشركة تعزز قدرتها على \\
\hline 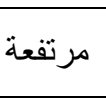 & 87.6 & 0.844 & 4.38 & 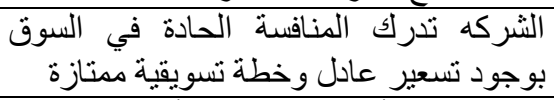 \\
\hline 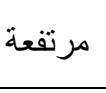 & 87.4 & 0.742 & 4.37 & تيطّب الثركة أن التتافس في الأسواق العالمية \\
\hline مرتفعة & 85 & 0.682 & 4.25 & وبعي البيع للخدمات لوجود خطدة تسويقية فعالة قبل \\
\hline مرتفعة & 83 & 0.668 & 4.15 & 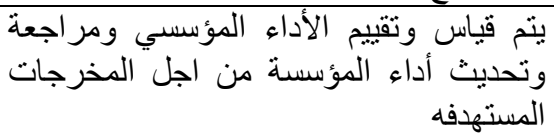 \\
\hline مرتفعة & 81.6 & 0.621 & 4.08 & الخدمات بشكل الديناميكية لهاد أهمية في توظيف \\
\hline مرتفعة & 87.192 & 0.443 & 4.36 & البيئة التنافسية \\
\hline
\end{tabular}


يتضح من الجدول أعلاه أن جميع الفقرات المعبرة عن درجة نأثير البيئة التنافسية في شركات

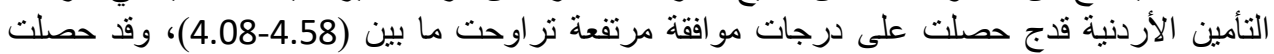

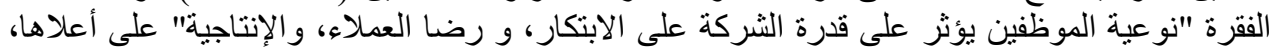

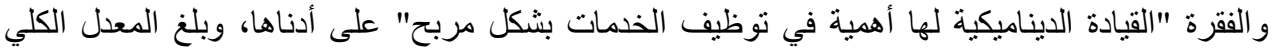

(4.36) وهو معدل ذو درجة مرتفعة.

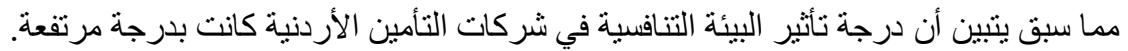

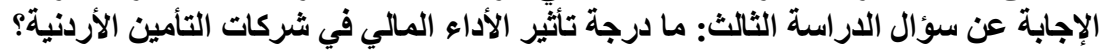

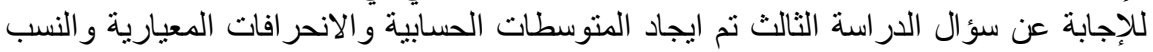
و الدرجات، و الجدول الآتي يبين ذلك: الك:

\begin{tabular}{|c|c|c|c|c|}
\hline 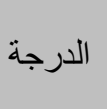 & $\%$ & 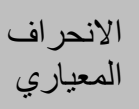 & 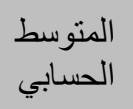 & 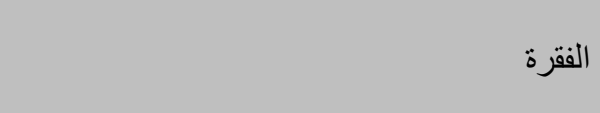 \\
\hline 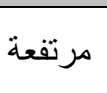 & 91.6 & 0.605 & 4.58 & 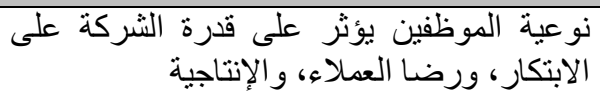 \\
\hline 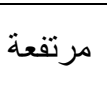 & 89.6 & 0.671 & 4.48 & الابداع والابتكار للارتفاع باداء الثركات يفرضات. ضرورة \\
\hline 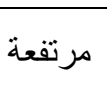 & 88.8 & 0.608 & 4.44 & بالعمليات المحاسبيّة الّْختلفة وفعال، وقادر على القيام \\
\hline 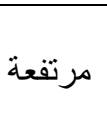 & 88.8 & 0.669 & 4.44 & 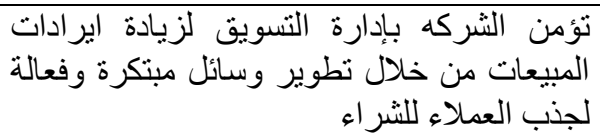 \\
\hline 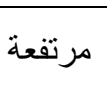 & 88.4 & 0.723 & 4.42 & الآصنول الرأسمالية للشركة تعزز قدرتها على الثرى \\
\hline 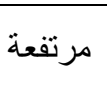 & 87.6 & 0.844 & 4.38 & تسعبر عادل وخطة تسوك الشيقة الحادة في السوق بوجود \\
\hline 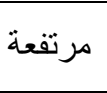 & 87.4 & 0.742 & 4.37 & تيتلب الثركة أن التنافس في الأسو اق العالمية \\
\hline 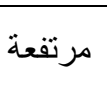 & 85 & 0.682 & 4.25 & تلعي الشركة لوجود خطة تسويقية فعالة قبل وبعد \\
\hline 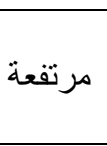 & 83 & 0.668 & 4.15 & 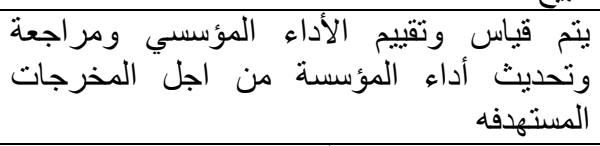 \\
\hline 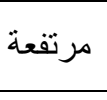 & 81.6 & 0.621 & 4.08 & بشكل مربح الديناميكية لها أهمية في توظيف الخدمات \\
\hline مرتفعة & 87.192 & 0.443 & 4.36 & البيئة التنافسية \\
\hline
\end{tabular}

يتضح من الجدول أعلاه أن جميع الفقرات المعبرة عن درجة الأداء المالي في شركات التأمين

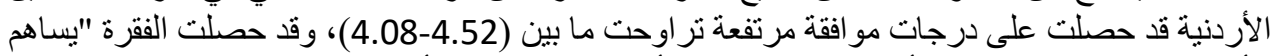

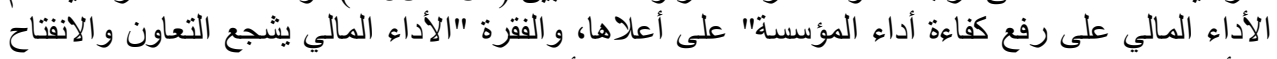

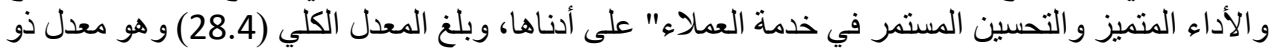
درجة مرتفعة. 


\section{Factors affecting performance of Jordanian Insurance Corporations in Jordan}

$$
\text { مما سبق يتبين أن درجة الأداء المالي في شركات التأمين الأردنية كانت بدرجة مرتفعة. }
$$

اختبار فرضيات الدراسة:

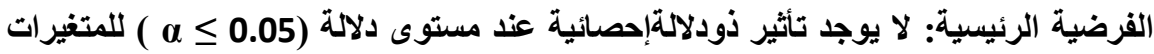

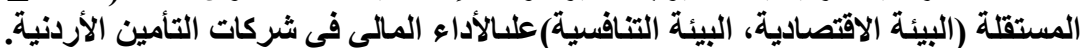

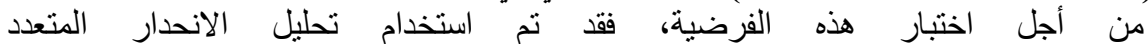
(MultipleRegression) حيث تم التأكد فبل استخدام هذا الأسلوب من عدم وجود ارتباط عالي بين التين

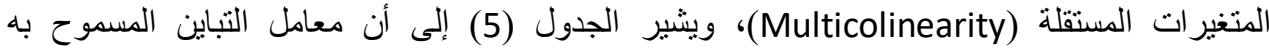
للمتغير ات المستقلة كان أقل من 1 و أكبر من 0.10 كما كانت قيم معامل تضخم التباين أقل من 10 حيث يثلئ يدل ذلك على عدم وجود ارتباط عالي بين المتغير ات المستقلة (Hair et al., 1988).

الجدول(5). نتائج اختبار قوة الارتباط بين المتغيرات المستقلة

\begin{tabular}{|c|c|c|}
\hline Tolerance & VIF & المتغير \\
\hline 0.625 & 1.601 & البيئة الاقتصادية \\
\hline 0.735 & 2.601 & البيئة التنافسية \\
\hline
\end{tabular}

الجدول(6). نتائج اختبار الاتحدار المتعدد لتأثير المتغيرات المستقلة في الأداء المالي

\begin{tabular}{|c|c|c|c|}
\hline Sig. & $\mathrm{t}$ & Beta & المتغير \\
\hline .254 & 1.154 & .128 & البيئة الاقتصادية \\
\hline \multirow[t]{5}{*}{$.000^{*}$} & 6.307 & .702 & البيئة التنافسية \\
\hline & & .788 & $\mathrm{R}$ \\
\hline & & 0.62 & $\mathrm{R} 2$ \\
\hline & & 40.034 & $\mathrm{~F}$ \\
\hline & & $0.000 *$ & دلالة F \\
\hline
\end{tabular}

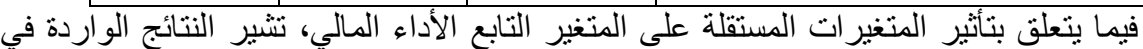

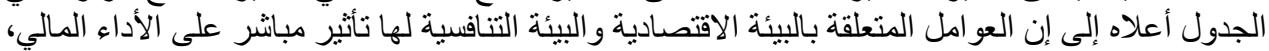

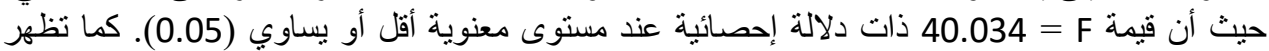
النتائج أن 62.2\% من الاختلافات الحاصلة في الأداء المالي تعود لدور البيئة الاقتصادية و التنافسية.

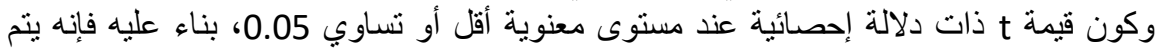

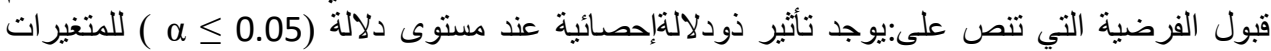

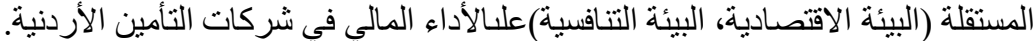

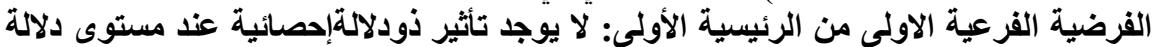

( $\alpha \leq 0.05)$

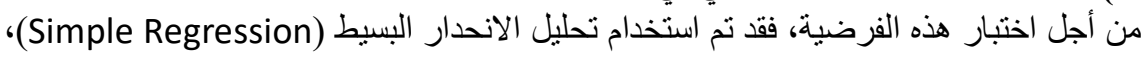

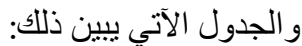
الجدول(7). نتائج اختبار الاتحدار البسيط لتأثير متغير البيئة الاقتصادية على الأداء المالي

\begin{tabular}{|c|c|c|c|}
\hline Sig. & $\mathrm{t}$ & Beta & المتغير \\
\hline \multirow[t]{4}{*}{$0.000 *$} & 4.764 & 0.559 & تخطيط الموارد البشرية \\
\hline & & .559 & $\mathrm{R}$ \\
\hline & & 0.312 & $\mathrm{R} 2$ \\
\hline & & 22.695 & $\mathrm{~F}$ \\
\hline
\end{tabular}

فيما يتعلق بتأثثر المتغير المستقل البيئة الاقتصادية على المتغير التابع الأداء المالي، تتثبر النتائج

أن قيمة 22.695 هي ذات دلالة إحصائية عند مستوى معنوية أقل أو يساوي (0.05). 
كما نظهر النتائج أن 31.2\% من الاختلافات الحاصلة في الأداء المالي تعود لمتغير البيئة الاقتصادية.

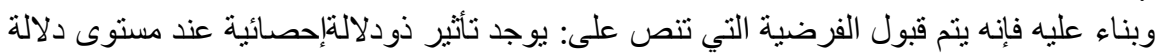

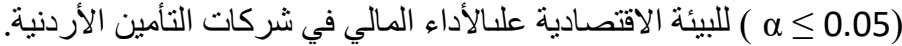

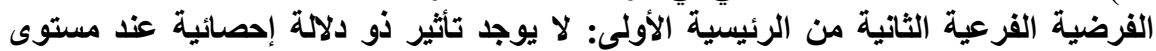

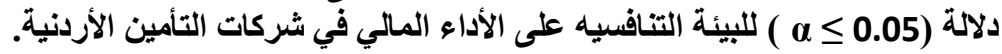
من أجل اختبار هذه الفرضية، فقد تم استخدام تحليل الانحدار البسيط (Simple Regression)، و الجدول الآتي يبين ذلك: التبن

\begin{tabular}{|c|c|c|c|}
\hline Sig. & $\mathrm{t}$ & Beta & المتغير \\
\hline $0.000^{*}$ & 8.844 & 0.781 & البيئة التنافسية \\
\hline & & .781 & $\mathrm{R}$ \\
\hline & & 0.61 & $\mathrm{R} 2$ \\
\hline & & 78.219 & $\bar{F}$ \\
\hline
\end{tabular}

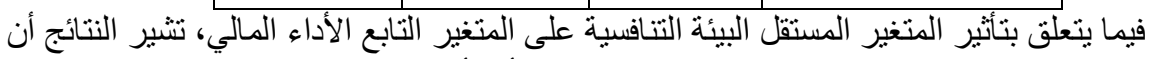
قيمة = F 78.219 هي ذات دلالة إحصائية عند مستوى معنوية أقل أو يساوي (0.05).

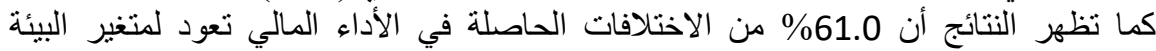

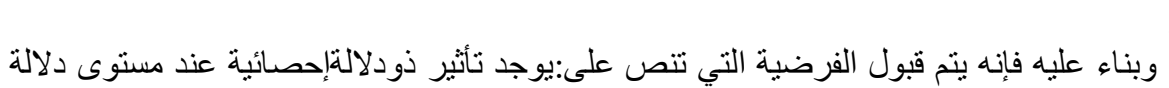

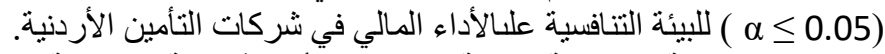

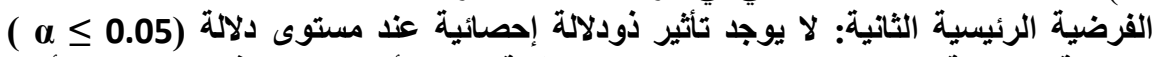

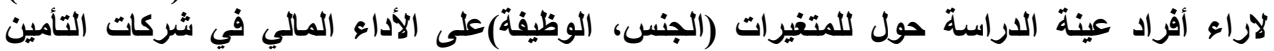
الفرعية الأولى من الرئيسية الثانية:لا يوجد تأثير ذودلالة إحصائية عند مستوى دلالة (0.05 الألئية الأردنية.

a

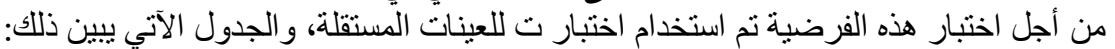
الجدول(9). نتائج اختبار ت للعينات المستقلة لتأثير متفير الجنس التسار تلفينات

\begin{tabular}{|c|c|c|c|c|c|c|}
\hline مستوى & الحرجية & قيمة T & الالنحر اف & الحسابي & العدد & الجنس \\
\hline \multirow{2}{*}{0.785} & \multirow{2}{*}{50} & \multirow{2}{*}{$-.274-$} & 0.490 & 4.27 & 39 & ذكر \\
\hline & & & 0.478 & 4.31 & 13 & أنثى \\
\hline
\end{tabular}

من خلال النتائج في الجدول أعلاه نلاحظ أن قيمة T لم تكن ذات دلالة احصائية عند مستوى أقل

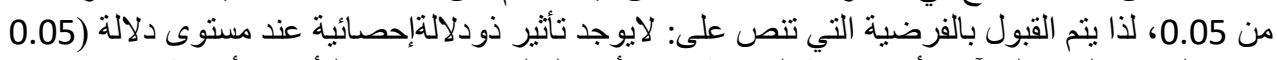

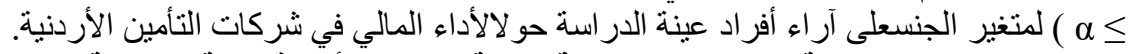

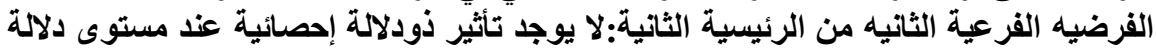

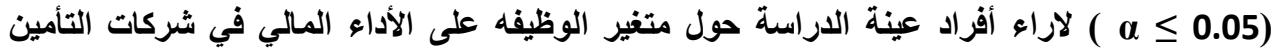
من أجل اختبار هذه الفرضية تم استخدام اختبار تحليل التباين الأحادي، والجدول الآتي يبين ذلك: الأردنية. 


\section{Factors affecting performance of Jordanian Insurance Corporations in Jordan}

\begin{tabular}{|c|c|c|c|c|c|c|c|}
\hline مستوى الدلالة & قيمة F & $\begin{array}{r}\text { Mean } \\
\text { Square }\end{array}$ & الحرجة & الانحر افياري & الحسابي & 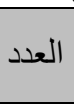 & الوظيفة \\
\hline \multirow{6}{*}{$0.008^{*}$} & \multirow{6}{*}{3.883} & \multirow{6}{*}{0.738} & \multirow{6}{*}{4} & 0.330 & 3.23 & 2 & مدير مالي \\
\hline & & & & 0.653 & 4.30 & 8 & رئيس محاسبين \\
\hline & & & & 0.402 & 4.32 & 34 & محاسب*** \\
\hline & & & & 0.236 & 4.83 & 2 & مدقق داخلي** \\
\hline & & & & 0.297 & 4.16 & 6 & مدقق خارجي* \\
\hline & & & & 0.483 & 4.28 & 52 & Total \\
\hline
\end{tabular}

من خلال النتائج في الجدول أعلاه نلاحظ أن قيمة F كانت ذات دلالة احصائية عند مستوى أقل

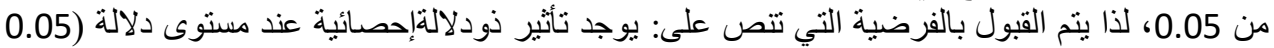

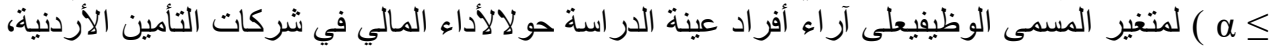

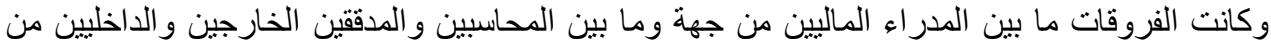
جهة لصالح المحاسبين والمدققين الخارجيين و الداخلين.

\section{النتائج والتوصيات

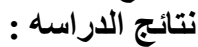

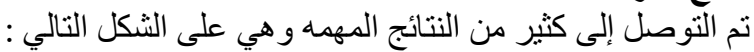

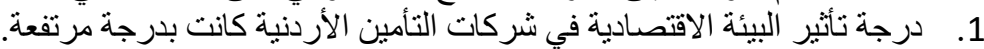

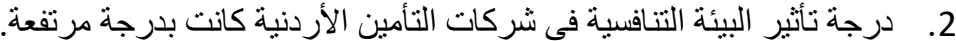

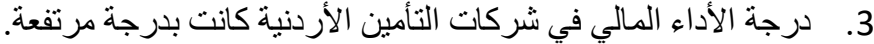

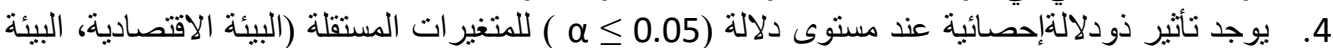

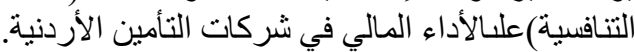

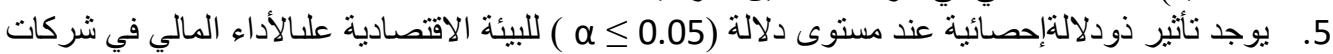

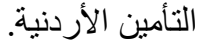
6. يوجد تأثير ذو دلالة إحصائية عند مستوى دلالة (0.05 a 0 ) للبيئة التنافسية على الأداء المالي في شركات التأمين الأردنية.

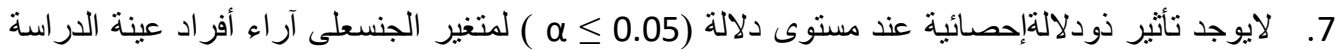

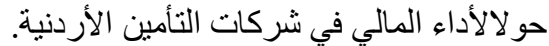

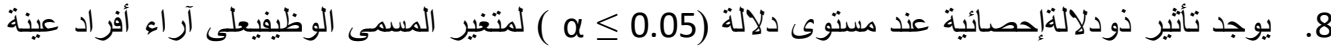

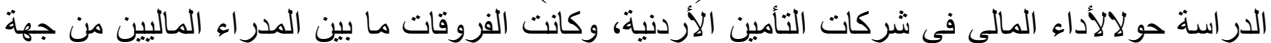

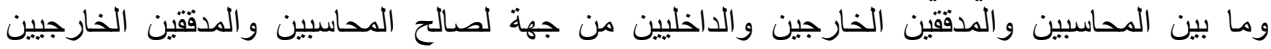

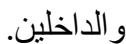

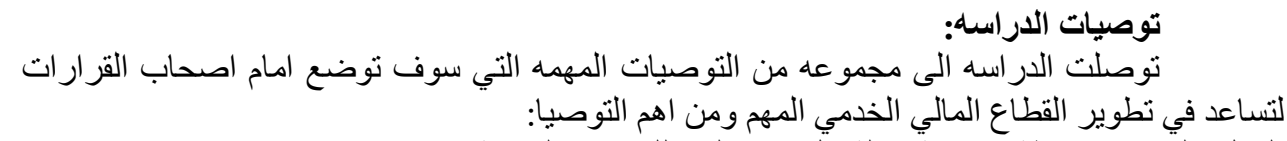

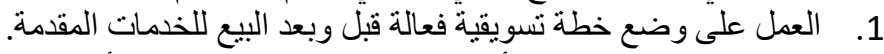

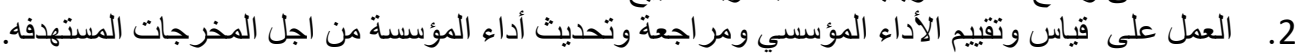

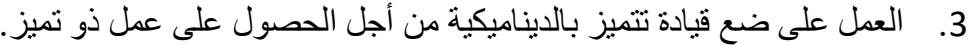

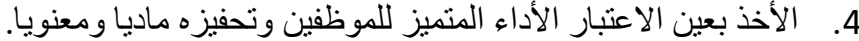

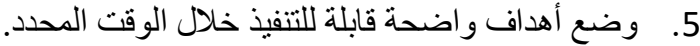
6. العمل على نشر ثقافة المر اجعة و التقييم. 


\section{Journal of Social Sciences (COES\&RJ-JSS), 8(4), pp.558-573}

$$
\text { 7. الأخذ بعين الاعتبار التحديات التى تو اجه الموظفين وتدريبهم وتطوير إمكاناته. }
$$

1. الوردات، خلف عبد الله (2010)، الرقابة الداخلية. مؤسسة الوراق للنشر و التوزيع، عمان، الأردن.

$$
\text { 2. الاتحاد الأردني لقطاع التأمين، (2012). }
$$

3. ازهر، بسام ودريباتي، يسيرة )(2011أهم المعوقات التي تواجه إدارة شركات التأمين، مجلةجامعة تثرين

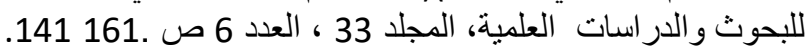

4. الاغوات ،توفيق ،(2014)،دور المؤشرات المالية في تقييم الأداء المالي لثركة البوتاس العربية ،رسالة

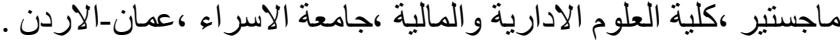

5. توفيق،عبد المحن،(2004)كتاب تقييم الأداء : مدخل جديد لعام جديد ، دار الفكر العربي مصر، ص3. 6. جودي، حمزة حيدر (2008) علاقة القرار الاستراتيجي في الأداء البنكي دراسه تحليلية(، مجلة الإدارة و الاقتصاد، الجامعة المستتصرية، العدد 64 .

دادن ، عبد الغني ،2007) قياس وتقييم الأداء المالي في المؤسسات الاقتصادية ، نحو إسر اء نموذج إنذار

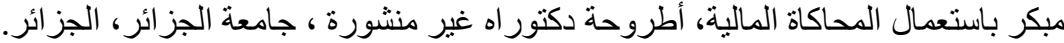

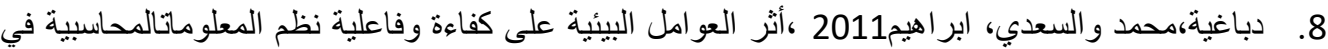

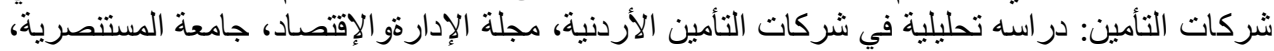

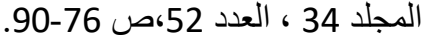

9. در اجي، عيسى (2010 البيئة و الميزة التتافسية في كل متطلبات التنمية المستدامة، ورقة مقدمة

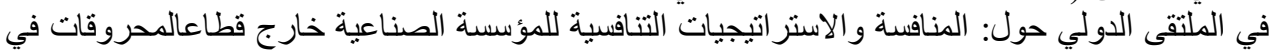

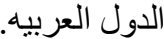

10. دز ايت ،خديجة ، مبروكة ،معطا الله ، (2012)، تقييم الأداء المالي للمؤسسة الاقتصادية (دراسة حالة

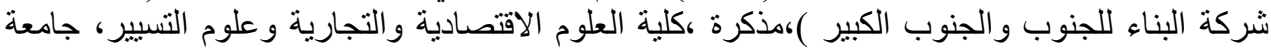

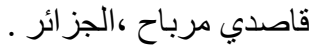

11. ساكر عبد الرحيم ومغز اوي عصام ،(2016) ، (المقارنة المرجعية أداء لتحسين الأداء المالي للمؤسسة

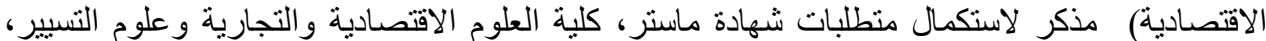

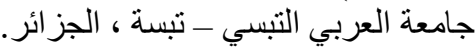

12. طبايبية ،سليمة ،(2009) تقييم الأداء المالي لثركات التأمين باستعمال النسب المالية (راسة حالة في الثركة الجزائرية للتأمين) ، رسالة ماجستير غير منشورة، جامعة 08 ماي 1945 فالمة ، الجزائر.

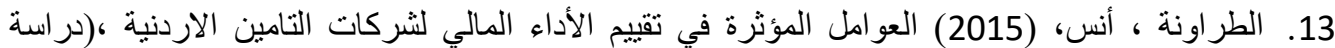

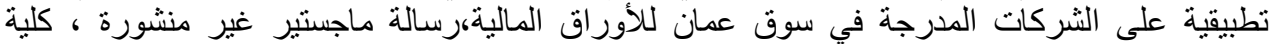
الاعمال ،جامعة الثرق الأوسط، الاردن. 


\section{Factors affecting performance of Jordanian Insurance Corporations in Jordan}

14. الطعامنة،ياسر حسني (2012)، تقييم الأداء المالي و الاقتصادي لثركات التأمين الإسلامية الأردنية مقارنة

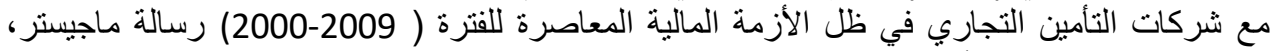
جامعة اليرموك، إربد، الأردن.

15. العامري،زهرة ، و الركابي ،علي، ( 2007)، اهمية النسب المالية في تقويم الاداء(دراسة ميدانية في

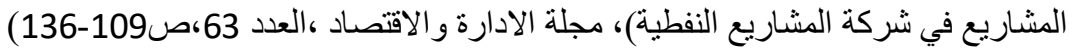

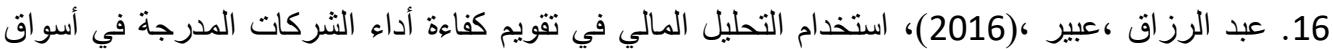
المال (دراسة حالة سوق الخرطوم للأوراق المالية). رسالة ماجستير إلى كلية التجارة ، جامعة التئة السودان

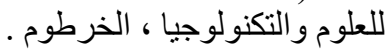

17. عبد القادر، طلحة، (2012)، محاولة قياس كفاءة الجامعة الجزائرية ، باستخدام اسلوب التحليل التطويقي للبيانات ، رسالة ماجستير غير منشورة ، جامعة ابي بكر بلقايد: الجزائر.

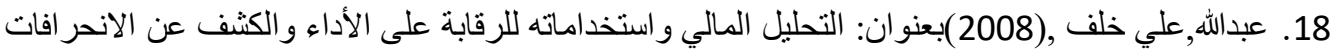
. رسالة ماجستير غير منشورة ،كلية الادارة والاقتصاد ،الاكاديمية العربية المفتوحة بالدانية الإلك.

19. عليان، زيد (2009)، مدى أهمية استخدام الموازنات التخطيطية في التخطيط والرقابة وتابة التقويم الاداء في

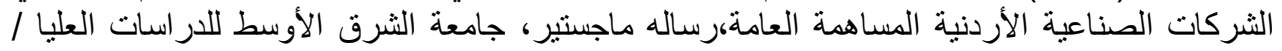
قسم المحاسبة

20. القضاة، مصطفى.(2015). "العو امل المؤثرة على الأداء المالي في الثركات المساهمة العامة الصناعية

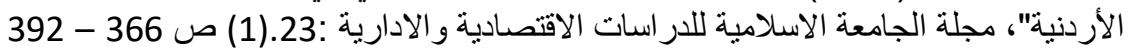

21. قمر، محمد ، (2009) تقييم أداء بنك فلسطين المحمود باستخدام بطاقة الأداء المتوازن رسالة ماجستير

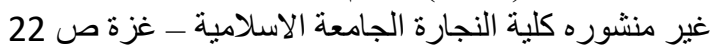

22. النجار ،جميل و عقل،علي.(2016)."قياس أثر الالتز ام بتطبيق قو اعد حوكمة الثركات على الأداء المالي:

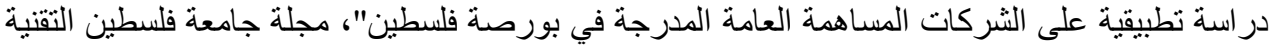

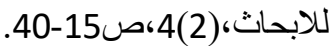

\section{References}

Al-Rawashdeh Firas, Omar Al Singlaw, (2016), The Existence of Fraud Indicators in Insurance Industry: Case of Jordan, International Journal of Economics and Financial Issues, 2016, 6(S5) 168-176.

Al-Rawashdeh Firas, (2016), Determinates of Demand on Purchasing Insurance Policies: Case of Jordan, International Review of Management and Marketing, Vol 6 Issue 4, p 1094-1102.

Ansari, V. \& Fola, W. (2014). Financial Soundness and Performance of Life Insurance Companies in India. International Journal of Research, 1(8). 
Journal of Social Sciences (COES\&RJ-JSS), 8(4), pp.558-573

Anwar Waseem, DEMIRHAN H, (2014) Factors Affecting The Financial Performance Of The Firms During The Financial Crisis: Evidence From Turkey, Ege Strategic Research Journal, 5(1) p 65-80

DeitianaTita, Habibuw Lionel, 2015, Factors Affecting the Financial Performance of Property Andreal Estate Companies Listed at Indonesia Stock Exchange, sian Business Review, V5(2) P 79-88.

Sasaka Peter, Gonga Mathews,(2017), Determinants Of Financial Performance Of Insurance Firms: A Survey Of Selected Insurance Firms In Nairobi County, The Strategic Journal of Business \& Change Management, Vol. 4, Iss. 4 (8), pp 123 143 